\title{
INTEGRAÇÃO TERRITORIAL NA AMÉRICA DO SUL: UMA ANÁLISE DOS PROJETOS DE INFRAESTRUTURA DOS PORTFÓLIOS DA IIRSA/COSIPLAN ${ }^{(*)}$
}

\author{
TERRITORIAL INTEGRATION IN SOUTH AMERICA: AN ANALYSIS OF THE \\ INFRASTRUCTURE PROJECTS OF IIRSA/COSIPLAN'S PORTFOLIOS
}

\author{
Vitor Hélio Pereira de Souza ${ }^{(* *)}$ \\ Universidade Federal de Santa Catarina, Florianópolis (SC), Brasil \\ Márcio Rogério Silveira ${ }^{(* * *)}$ \\ Universidade Federal de Santa Catarina, Florianópolis (SC), Brasil
}

Resumo: no ano 2000, foi lançada a Iniciativa para a Integração da Infraestrutura Regional Sul-americana (IIRSA), incorporada no ano de 2008 ao Conselho Sul-americano de Infraestrutura e Planejamento (COSIPLAN), iniciativas que retomaram o ideário integracionista latino-americano pelo prisma territorial. Desta maneira, este artigo objetivou compreender como ocorreu a distribuição espacial, setorial e subsetorial das obras e investimentos em infraestrutura de integração entre os países da América do Sul, por meio de uma análise exploratória dos Portfólios Gerais da IIRSA e do COSIPLAN, para o período do ano de 2000 a 2011.

Palavras-chaves: Infraestrutura de Integração; Interações Especiais; Desenvolvimento Regional.

Abstract: In 2000 the Initiative for South American Regional Infrastructure Integration (IIRSA) was launched, and at 2008 incorporated to the South American Consil of Infrastructure and Planning (COSIPLAN); those initiatives reward Latin America integrationist ideals by territorial prism. Thus, this article aim to understand how spatial, sector and sub-sector distribution of works and investments in infrastructure integration among South America countries occurred, through IIRSA and COSIPLAN General Portfolios, between the period of 2000 at 2011.

Keywords: Infrastructure Integration; Spatial Interactions; Regional Development.

(*) Este artigo resulta da revisão da dissertação de mestrado Integração territorial na América do Sul: uma análise multiescalar a partir das obras da IIRSA/COSIPLAN. Agradecemos o auxílio financeiro do Conselho Nacional de Desenvolvimento Científico e Tecnológico (CNPq) e da Fundação de Amparo à Pesquisa do Estado de São Paulo - FAPESP.

(**) Mestre, Aluno do Curso de Doutorado em Geografia da Universidade Federal de Santa Catarina; bolsista da Coordenação de Aperfeiçoamento de Pessoal de Nível Superior (CAPES); Pesquisador do Grupo de Estudos em Desenvolvimento Regional e Infraestrutura (GEDRI).E-mail: <vitorgedri@hotmail.com>.

$(* * *)$ Doutor, Professor adjunto do Departamento de Geociências da Universidade Federal de Santa Catarina (UFSC); Professor do Programa de Pós-graduação em Geografia da UFSC; Coordenador do Grupo de Estudos em Desenvolvimento Regional e Infraestrutura (GEDRI).E-mail: <marcio.silveira@ufsc.br>. Recebidoem:18.08.2014, aceito em 28.11.2014. 


\section{INTRODUÇÃO}

No ano 2000, em meio à comemoração dos 500 anos de descobrimento do Brasil, foi realizado, a convite do presidente brasileiro, Fernando Henrique Cardoso (19952003), o primeiro encontro de presidentes da América do Sul em Brasília, que contou com a participação dos doze mandatários dos países sul-americanos, apresentando como pautas diversas temáticas que interessavam ao conjunto de países, como: a democracia, o problema das drogas ilícitas, os crimes, a produção do conhecimento, o comércio e as infraestruturas de integração (COUTO, 2010).

Entretanto, a temática que demonstrou maiores avanços foi a última, por meio do lançamento da IIRSA. Essa objetivava ser um programa de obras multissetorial, multinacional e multidisciplinar, cuja intenção era a de melhorar e ampliar as infraestruturas físicas e, por conseguinte, elevar a competitividade da região no comércio mundial, possibilitando saldos positivos para a balança comercial dos países-membros.

A pesquisa aqui apresentada visou evidenciar o processo de conformação das desigualdades regionais no que diz respeito à distribuição territorial das infraestruturas de transporte, energia e comunicação para América do Sul. Prontamente, para alcançar tais resultados, a metodologia foi pautada em revisão bibliográfica, atrelada à análise de dados secundários, que resultaram em mapas elaborados com software ArcGIS. Por fim, foram realizadas entrevistas em órgãos como a coordenadoria-geral de planejamento da "Secretaria de Política Nacional de Transportes" no Brasil e a "Dirección Nacional de Planificación de la Integración Territorial Internacional" na Argentina, entre outros.

Logo, propomos brevemente apontar alguns aspectos dos projetos que compuseram a Agenda de Implementação Consensuada (AIC) e a Agenda de Projetos Prioritários de Integração (API), documentos que foram objeto de diversas investigações acadêmicas. E, na sequência, enquanto objetivo principal desse trabalho, visamos realizar uma análise exploratória dos "Portfólios" da IIRSA e do COSIPLAN, documentos pouco mencionados nas análises acadêmicas que correspondem a uma extensa lista de obras, cuja análise evidencia um importante panorama da distribuição territorial das infraestruturas e investimentos, promovidos nos últimos anos na América do Sul.

\section{A ARQUITETURA DO IIRSA/COSIPLAN}

Sendo assim, em dezembro de 2000, os Ministros do Transporte, Energia e Comunicações dos países participantes reuniram-se em Montevidéu (Uruguai). Naquele momento, foram estabelecidos os princípios que orientariam a iniciativa, segundo documento da IIRSA, dos quais se destacavam:

I. regionalismo aberto: visa ampliar o comércio exterior no âmbito regional, mas também extrarregional;

II. eixos de Integração e Desenvolvimento (EID): são obras de infraestruturas que perpassam o território de vários países, apresentando uma função transnacional; 
III. sustentabilidade socioambiental e político-institucional: implica na elaboração de dispositivos que garantam a maior participação da comunidade na decisão dos empreendimentos realizados, buscando reduzir os impactos socioambientais;

IV. aumento do valor agregado da produção: visa à consolidação de cadeias produtivas que fortaleceriam a complementaridade entre as economias da região e a fomentação de setores de alta competitividade internacional;

V. tecnologias de informação: busca incentivar a elaboração/difusão de conhecimento sobre os países sul-americanos, favorecendo o planejamento governamental, as estratégias adotadas dos setores produtivos e a educação;

VI. convergência normativa: almeja, por meio da intensificação do diálogo entre as autoridades reguladoras e de planejamento dos diversos países, estabelecer consenso, principalmente no que tange às questões relativas ao financiamento de obras realizadas por um conjunto de países, além do afinamento das regras que definem a atuação da iniciativa privada na região;

VII. coordenação público-privada: objetiva o estabelecimento de um ambiente regulatório para o desenvolvimento de parcerias público-privadas, estabelecendo os deveres e obrigações, além de possíveis riscos e benefícios às parcerias firmadas.

Para tanto, a iniciativa seria composta por uma estrutura institucional apoiada em órgãos nacionais e regionais já efetivos, com o propósito de realizar o aproveitamento do capital humano (know-how) existente, reduzindo os custos e o tempo necessário para a formação de uma nova equipe. Deste modo, a iniciativa foi organizada em quatro níveis:

I. Grupos Técnicos Executivos (GTE) - em cada Eixo de Integração e Desenvolvimento (EID) e em cada Processo Setorial de Integração (PSI), conformaram-se equipes, compostas por especialistas indicados pelos países participantes; mediante estudos, as equipes se tornaram responsáveis pela seleção das obras que viriam a compor o Portfólio da iniciativa, assim como propuseram alternativas para o equacionamento das questões normativas;

II. Comitê de Coordenação Técnica (CCT) - composto pela Corporação Andina de Fomento (CAF), pelo Fundo Financeiro para o Desenvolvimento da Bacia da Prata (FONPLATA) e pelo Banco Interamericano de Desenvolvimento (BID). Visa oferecer apoio técnico e financeiro à iniciativa, por meio de fundos "brandos" para custear estudos e projetos, além de realizar a divulgação de informações sobre a iniciativa. Já no ano de 2003, o comitê passou a contar, também, com o financiamento do Banco Nacional de Desenvolvimento Econômico e Social (BNDES), que passou a possibilitar maior autonomia às tomadas de decisões;

III. Coordenação Nacional (CN) - articula as informações das diversas instâncias governamentais, criando mecanismos para viabilizar a participação do setor privado e da sociedade civil. Para tanto, esta realiza, geralmente, duas reuniões ao ano, momento em que são analisados os avanços dos planos de execução da agenda de obra;

IV. Comitê de Direção Executiva (CDE) - constituído, normalmente, por ministros do planejamento ou da infraestrutura de cada país, que se reúnem uma vez ao ano, para avaliar os planos e redefinir as estratégias de trabalho para o próximo ano. 
No período de 2003 a 2004, foi elaborada a "Metodologia de Planejamento Territorial Indicativa" e, por conseguinte, foi realizado o "Ordenamento da Carteira de Projetos" da IIRSA. Tal proposta pautou-se em um viés geoeconômico do território, cuja organização passou a ser pensada por meio das infraestruturas de integração e dos aspectos regulatórios que incidem sobre as mesmas (IIRSA, 2006).

Sendo assim, foram definidos Eixos de Integração e Desenvolvimento (EID), isto é, definiu-se um recorte espacial multinacional articulado por infraestruturas de integração que buscam, mediante metas comuns, dinamizar as economias dessas regiões, por meio da implantação de uma cadeia logística integrada. Vale frisar ainda que houve também o estabelecimento de sete Processos Setoriais de Integração (PSI), a saber: tecnologias de informação e das comunicações, sistemas operacionais de transporte aéreos, facilitação de passos de fronteira, sistemas operacionais de transporte marítimo, integração energética, sistema de transporte multimodal e sistemas de financiamento (IIRSA, 2006). Estes, mais tarde, foram reduzidos a quatro.

Para a concretização dos EIDs e dos PSIs foram levados em consideração os seguintes critérios:

I. a cobertura geográfica dos países e regiões, que visava, por meio de infraestruturas, fomentar a integração de regiões que apresentam grandes concentrações populacionais;

II. os fluxos existentes, que objetivavam identificar as regiões e as infraestruturas por onde perpassava a maior intensidade de fluxos comerciais, no intuito de melhorar/ ampliar a capacidade dessas infraestruturas;

III. os fluxos potenciais, que almejavam promover o reconhecimento das áreas com presença de recursos naturais, cujos investimentos em infraestrutura podem favorecer o desenvolvimento de produtos exportáveis;

IV. a sustentabilidade socioambiental, pela qual buscou-se, em tese, considerar na elaboração dos projetos a diversidade ambiental e cultural de cada região, incluindo áreas protegidas, reservas florestais e reservas indígenas, almejando reduzir os impactos ambientais dos projetos.

O resultado foi a definição de 12 Eixos de Integração e Desenvolvimento (EID). No entanto, na V Reunião do Comitê de Direção Executiva em 2003, esses foram reduzidos a dez EID: Andino, Andino do Sul, Capricórnio, Hidrovia Paraguai-Paraná, Amazonas, Escudo Guianês, do Sul, Interoceânico Central, Peru-Brasil-Bolívia e MERCOSUL-Chile (abarca a região do MERCOSUL, mais o Chile) (IIRSA, 2006, 2010, 2011). Deve-se chamar a atenção para o fato de que esses eixos, delimitados por grandes infraestruturas, encontram-se sobrepostos, mas ainda assim muitas vezes apresentam dinâmicas econômicas que extrapolam o recorte territorial adotado pelo projeto.

Tais EIDs, enquanto um esforço de regionalização orientados por eixos de infraestrutura, abarcam áreas que demonstram uma grande discrepância em relação a diversas variáveis, como a extensão territorial abrangida, a população e o Produto Interno Bruto (PIB). Percebe-se que somente os EID Amazonas e o Andino possuem uma área territorial correspondente a 50,5\%, e 54,4\% do continente sul-americano. Já em relação ao 
número de população e ao Produto Interno Bruto (PIB), o eixo Andino concentrava aproximadamente $82,8 \%$ e $86,4 \%$, enquanto o eixo MERCOSUL-Chile, $53,7 \%$ e $61,3 \%$ para os respectivos índices.

Para um melhor planejamento dos EIDs delimitados, estes foram classificados conforme os fluxos econômicos existentes em Eixos com dinâmica de integração preestabelecidos, que já possuíam concentração populacional, dinâmica comercial e infraestrutura de integração de relativa qualidade, como foi o caso dos EID Andino e o MERCOSUL-Chile, que abarcam respectivamente a Comunidade Andina (CAN) e o Mercado Comum do Sul (MERCOSUL). Por sua vez, os Eixos Emergentes apresentavam potencial de crescimento, entretanto, a precariedade ou inexistência de infraestrutura física adequada tornava-se um entrave para o seu desenvolvimento, como era a situação dos demais EID: Andino do Sul, Capricórnio, Hidrovia Paraguai-Paraná, Amazonas, Escudo Guianês, Sul, interoceânico Central, Peru-Brasil-Bolívia.

Cada eixo apresenta peculiaridades, sendo fundamental a realização de estudo de maior fôlego sobre a dinâmica econômica e as implicações decorrentes dos projetos da IIRSA em cada um desses recortes territoriais. Essa delimitação possibilitou que, no período de 2003 a 2004, fossem selecionadas e hierarquizadas as obras de infraestrutura que viriam a integrar o Portfólio de obras da IIRSA, composto, inicialmente, por 335 projetos com investimentos estimados em US\$ 37.425 milhões, que alcançariam no ano de 2010 o total de 524 projetos, com investimentos programados de US\$ 96.119,2 milhões, configurando-se atualmente em uma das maiores carteiras de investimentos direcionadas às infraestruturas no mundo (IIRSA, 2011).

Sendo assim, para cada EID foram identificados projetos de maior importância, definidos como Projeto Âncora - obras de grande porte, que canalizam os fluxos que deverão ser repassados também para outras vias - e Projetos Rótulas, que são compostos por obras que interligam diferentes grupos de projetos pertencentes ao mesmo ou a outro EID.

Desta maneira, em novembro de 2004, foi selecionado em meio ao Portfólio da IIRSA um grupo constituído por 31 obras, geralmente Projetos Âncora com nível avançado de preparação, que viriam a compor a Agenda de Implementação Concensuada (AIC) para o período de 2005-2010. Logo, esse pacote de obras alcançaria destaque com a IIRSA, sendo utilizado para o marketing governamental do projeto e tornando-se objeto de grande parte das análises acadêmicas.

Prontamente, a partir do ano de 2009, sob a responsabilidade da UNASUL (União das Nações Sul-americanas), a IIRSA foi incorporada como foro técnico de infraestrutura do recém-criado Conselho Sul-americano de Infraestrutura e Planejamento (COSIPLAN). Esse órgão tornou-se responsável pelas questões infraestruturais e por atualizar a agenda de obras da IIRSA visando "Aprofundar e aperfeiçoar os avanços alcançados na identificação, evolução e implementação dos projetos de integração no marco do processo de planejamento de escala regional, que realizam os países da América do Sul" (COMUNIDADE SUL-AMERICANA DE NAÇÕES, 2006 - tradução nossa).

Para tanto, o COSIPLAN manteve, enquanto ideal, a busca pela integração dos setores de energia e de transporte. Este último, objetivava reduzir os custos logísticos e pro- 
mover a ampliação da complementaridade produtiva, com destaque para as indústrias de pequeno e médio porte, enquanto medida para alcançar o desenvolvimento econômico e social, atrelado, em tese, à sustentabilidade ambiental e ao respeito aos povos.

Assim sendo, no ano de 2011, foi lançado o Plano de Ação Estratégica (PAE) com objetivo de orientar os trabalhos da iniciativa nos próximos dez anos. Tal plano, mediante uma série de discussões, agregou os progressos da IIRSA, entre eles a "Metodologia de Planejamento Territorial Indicativo" e as ferramentas metodológicas do antigo projeto. O resultado foi a atualização do antigo Portfólio da IIRSA, por meio do estabelecimento de um novo Portfólio composto por 531 projetos e com investimentos estimados em US\$ 116.120,6 milhões (UNASUR, 2012).

Seguindo o mesmo padrão da IIRSA, na reunião de julho de 2011, todas as coordenações nacionais apresentaram propostas de projetos. Por conseguinte, por meio do diálogo entre os países, tais demandas expostas na PAE convergiram para uma agenda com projetos estruturados de maiores dimensões (UNASUR, 2012).

Deste modo, assim como na IIRSA, foi definido um portfólio com os principais projetos. Na reunião de agosto do mesmo ano, o COSIPLAN criou a Agenda de Projetos Prioritários de Integração (API), que visava “(...) Promover a conectividade na região a partir da construção e operação eficiente de infraestruturas para sua integração física, atendendo a critérios de desenvolvimento social e econômico sustentáveis, preservando o meio ambiente e o equilíbrio dos ecossistemas" (Estatuto do COSIPLAN, artigo $4^{\circ}$ - tradução nossa).

Portanto, a API foi composta por projetos classificados como "Projetos Estruturados", ou seja, obras que favorecem as redes de conectividade física, com alcance regional e com potencial de fomentar sinergias e de solucionar as deficiências da infraestrutura existente e, consequentemente, "Projetos Individuais", aqueles que apresentam função complementar aos projetos estruturados, geralmente projetos de menor porte (UNASUR, 2012).

\section{A IIRSA E O COSIPLAN: AS REAIS DIMENSÕES DOS ROBUSTOS PORTFÓLIOS}

O Portfólio de obras da IIRSA foi elaborado para o período de 2003 a 2004, porém, por causa do grande enfoque dado ao AIC, foi frequentemente desfavorecido nas análises acadêmicas, pois geralmente tratava de projetos de menor envergadura. No entanto, estes portfólios, nos últimos anos, passaram por diversas atualizações, evoluindo no período de 2003 a 2010 de 335 projetos para um total de 524, um aumento de 56\% no número de obras; por sua vez, os investimentos saltariam de US\$ 37.425 milhões para US\$ 96.119,2 milhões, ampliando em 157\% o orçamento do Portfólio (IIRSA, 2011).

Embora tais projetos escolhidos pareçam de cunho pontual, o leitor pode questionar qual a importância dos mesmos diante da agenda principal (AIC e API). Ora, deve-se advertir que a realização desses projetos tem caráter complementar aos demais projetos que devem ser realizados em cada país.

Sendo assim, no período de 2003 a 2004, o Portfólio da iniciativa estava composto por 335 projetos, distribuídos por 9 EID (não foi contemplado o EID Andino do Sul), 
sendo que os eixos que concentravam o maior número de projetos eram os EID de Dinâmica de Integração Estabelecida, a saber: o Andino com 74 e o MERCOSUL-Chile com 68 , que respondiam juntos por $42 \%$ dos projetos. Já ao averiguar o valor dos investimentos do Portfólio com um total de US\$ 37.425 milhões, o EID MERCOSUL-Chile foi responsável por US\$ 12.076 milhões, seguido pelo EID Emergente, Peru-Brasil-Bolívia, que, embora com apenas 18 projetos, apresentou investimentos estimados em US\$ 11.588 milhões.

Por conseguinte, para o período de 2005-2006, ocorreram poucas modificações no Portfólio, no entanto, houve a inclusão de um novo Projeto Âncora no Eixo Amazonas, sendo incorporados 10 novos projetos ao Portfólio. Já o EID Capricórnio e MERCOSUL-Chile tiveram, cada um, 2 novos projetos adicionados, além de 1 projeto âncora ajustado. Tais alterações aumentaram o número de iniciativas que compunham o Portfólio para 349, resultando também no aumento dos investimentos em US\$ 455 milhões, totalizando US\$ 37.880 milhões.

Já no ano de 2007 foi realizada a primeira reunião do EID Hidrovia Paraguai-Paraná. Dela resultou a identificação de cinco novos grupos de projetos (âncora), acrescentando mais 98 obras ao Portfólio, com acréscimo de US\$2.829 milhões nos investimentos. Ademais, todos os EID, exceto o EID Andino e Escudo das Guianas, ampliaram o seu número de projetos resultando em 155 novas obras, que totalizaram 504 projetos ao Portfólio. Do mesmo modo, todos os EID expandiram as suas necessidades de investimentos - que quase dobraram - atingindo a cifra de US\$ 68.271,4 milhões.

Posteriormente, entre o período de 2008 a 2009, houve a incorporação de novos projetos, como foram os casos dos EIDs Capricórnio, Interoceânico e o MERCOSUL-Chile. Já outros EIDs, como o da Hidrovia Paraguai-Paraná e do Escudo das Guianas, reduziram o número de projetos, embora tenha havido novamente a ampliação dos investimentos em todos os EID, exceto nos EIDs Escudo das Guianas, Interoceânico e Peru-Brasil-Bolívia. Deste modo, termina-se esse período com 510 projetos e US\$ 74.542 milhões de investimentos estimados.

Por fim, no ano de 2010, antes da IIRSA tornar-se COSIPLAN, todos os eixos incorporaram novos projetos, menos no EID Andino, Escudo das Guianas e o Peru-Brasil-Bolívia que mantiveram o mesmo número de projetos anteriores. Desta maneira, nos demais eixos, houve a incorporação de 14 novas obras ao Portfólio, totalizando 524 projetos com investimentos estimados em US\$ 21.577 milhões, totalizando US\$ 96.119,2 milhões. Conforme balanço apresentado para o ano, a situação era de apenas 53 (10\%) projetos concluídos, 175 (34\%) estavam em execução, 158 (30\%) em pré-execução e 138 (26\%) em fase de perfil.

O Portfólio de obras apresentava uma tendência à concentração de projetos e investimentos no EID MERCOSUL-Chile, que apresentou 107 projetos e investimentos estimados em US\$ 35.836 milhões, seguido em número de projetos pelo EID Hidrovia Paraguai-Paraná, com 95 projetos e o EID Capricórnio, com 72 projetos. Ora, ainda que possa passar despercebido, deve-se chamar atenção para o fato de que os 3 EID aqui salientados compõem a Região do Cone Sul, demonstrando uma tendência articuladora que essa área possui em relação às demais regiões da América do Sul, haja vista que juntos os mesmos respondem também pela maior parte dos investimentos (Tabela 01). 
A partir do ano de 2011, os projetos de integração infraestruturais sul-americano tornaram-se responsabilidade da COSIPLAN. Certamente, existiram modificações na agenda de obras, que foram ampliadas de 524 para 531, assim como na estimativa de investimentos, que saltaram de US\$ 96.119 milhões para US\$ 116.120,6 milhões (UNASUR, 2012). Entretanto, como poderemos verificar, as permanências são amplas ${ }^{(1)}$.

\begin{tabular}{|c|c|c|c|c|c|c|c|c|c|c|}
\hline \multicolumn{11}{|c|}{$\begin{array}{c}\text { Tabela } 01 \text { - Grupos de trabalho, número de projetos e investimentos estimados do Port- } \\
\text { fólio de Projetos da IIRSA }(2003 / 2010 \text { em milhões US\$ por ano })^{(1)}\end{array}$} \\
\hline \multicolumn{11}{|c|}{ EIDs } \\
\hline & MCC & CAP & HPP & SUR & AND & PBB & ESG & IOC & AMA & Total $\mathrm{a} / \mathrm{b}$ \\
\hline \multicolumn{11}{|c|}{2003 a 2004} \\
\hline$P$ & 68 & 34 & & 21 & 74 & 18 & 32 & 44 & 44 & 335 \\
\hline 1 & 12.076 & 2.031 & & 1.071 & 4.975 & 11.588 & 366 & 3.306 & 2.011 & 37.425 \\
\hline \multicolumn{11}{|c|}{2005 a 2006} \\
\hline$P$ & 71 & 36 & & 21 & 73 & 18 & 32 & 44 & 54 & 349 \\
\hline 1 & 12.161 & 2.031 & & 1.071 & 4.975 & 11.588 & 366 & 3.306 & 2.382 & 37.880 \\
\hline \multicolumn{11}{|c|}{2007} \\
\hline $\mathrm{P}$ & 91 & 63 & 98 & 26 & 65 & 23 & 32 & 49 & 57 & 504 \\
\hline 1 & 19.465 & 6.083 & 2.829 & 2.530 & 6.097 & 17.561 & 5.847 & 4.651 & $3.208,4$ & 68.271 \\
\hline \multicolumn{11}{|c|}{2008 a 2009} \\
\hline$P$ & 105 & 69 & 88 & 26 & 65 & 23 & 25 & 54 & 57 & 510 \\
\hline 1 & 29.399 & 7.945 & 3.974 & 2.533 & 7.050 & 12.888 & 927 & 4.576 & 5.281 & 74.542 \\
\hline \multicolumn{11}{|c|}{2010} \\
\hline$P$ & 107 & 72 & 95 & 27 & 64 & 23 & 25 & 55 & 58 & 524 \\
\hline 1 & 35.836 & 9.421 & 6.677 & 2.713 & 7.478 & 21.402 & 1.695 & 5.525 & 5.401 & 96.119 \\
\hline \multicolumn{11}{|c|}{2003 a 2004} \\
\hline$P$ & 68 & 34 & & 21 & 74 & 18 & 32 & 44 & 44 & 335 \\
\hline 1 & 12.076 & 2.031 & & 1.071 & 4.975 & 11.588 & 366 & 3.306 & 2.011 & 37.425 \\
\hline \multicolumn{11}{|c|}{2005 a 2006} \\
\hline$P$ & 71 & 36 & & 21 & 73 & 18 & 32 & 44 & 54 & 349 \\
\hline 1 & 12.161 & 2.031 & & 1.071 & 4.975 & 11.588 & 366 & 3.306 & 2.382 & 37.880 \\
\hline \multicolumn{11}{|c|}{2007} \\
\hline $\mathrm{P}$ & 91 & 63 & 98 & 26 & 65 & 23 & 32 & 49 & 57 & 504 \\
\hline $\mathrm{I}$ & 19.465 & 6.083 & 2.829 & 2.530 & 6.097 & 17.561 & 5.847 & 4.651 & $3.208,4$ & 68.271 \\
\hline \multicolumn{11}{|c|}{2008 a 2009} \\
\hline$P$ & 105 & 69 & 88 & 26 & 65 & 23 & 25 & 54 & 57 & 510 \\
\hline 1 & 29.399 & 7.945 & 3.974 & 2.533 & 7.050 & 12.888 & 927 & 4.576 & 5.281 & 74.542 \\
\hline \multicolumn{11}{|c|}{2010} \\
\hline $\mathrm{P}$ & 107 & 72 & 95 & 27 & 64 & 23 & 25 & 55 & 58 & 524 \\
\hline 1 & 35.836 & 9.421 & 6.677 & 2.713 & 7.478 & 21.402 & 1.695 & 5.525 & 5.401 & 96.119 \\
\hline
\end{tabular}

Fonte: IIRSA, 10 anos depois: Suas conquistas e desafios, 2011.

Nota-se que o EID MERCOSUL-Chile continuou concentrando o maior número de obras, com $105(19,7 \%)$ e US\$ 44.389,8 (38,2\%) dos investimentos, seguido pelo

(1) Nota: (I.) Investimentos. (P.) Número de Projetos. Os totais de "Número de Projetos" e de "Investimentos Estimado" mencionados não se relacionam à soma aritmética dos totais por EID (US\$96.149,2), já que existem dois projetos rótula: (i) Passo de Fronteira Pircas Negras pertencentes aos Eixos de Capricórnio e MERCOSUL-Chile; e (ii) Construção da Ferrovia Cascavel - Foz do Iguaçu pertencentes aos Eixos de Capricórnio e à Hidrovia Paraguai-Paraná. 
EID Hidrovia Paraguai-Paraná, com 93 (17,4\%) obras e US\$ 6.514,8 (5,6\%) dos investimentos e pelo EID Capricórnio, com 76 (14,2\%) obras e US\$ 8.979,1 (7,7\%,) dos investimentos, ou seja, grandes parcelas das obras e dos investimentos continuaram sendo canalizadas pela Região do Cone Sul (Tabela 02; Mapa 01).

\section{Tabela 02 - Número de grupos de trabalho, obras e investimentos por EID} (em milhões de US\$) para o ano de 2011

\begin{tabular}{l|r|r|r|r}
\hline \multicolumn{1}{c|}{ EID } & \multicolumn{1}{c|}{ TOTAL } & \multicolumn{1}{c|}{ \% } & \multicolumn{1}{c}{ US\$ (1) } & \multicolumn{1}{c}{ \% } \\
\hline MERCOSUL-Chile & 105 & 19,7 & $44.389,8$ & 38,2 \\
\hline Hidrovia Paraguai-Paraná & 93 & 17,4 & $6.514,8$ & 5,6 \\
\hline Capricórnio & 76 & 14,2 & $8.979,1$ & 7,7 \\
\hline Andino & 64 & 12,0 & $9.343,5$ & 8,0 \\
\hline Amazônico & 64 & 12,0 & $6.099,9$ & 5,2 \\
\hline Interoceânico Central & 61 & 11,4 & $4.112,7$ & 3,5 \\
\hline Sul & 27 & 5,1 & $2.738,0$ & 2,5 \\
\hline Peru-Brasil-Bolívia & 25 & 4,7 & $29.557,8$ & 25,4 \\
\hline Escudo Guianês & 18 & 3,5 & $4.540,3$ & 3,9 \\
\hline Total (2) & 531 & 100 & $116.120,6$ & 100,0 \\
\hline
\end{tabular}

Fonte: IIRSA - COSIPLAN, 2011.

Ao analisar a composição setorial do Portfólio em relação ao número de obras programadas para o ano de 2010, percebemos que a IIRSA, embora almejasse ser um projeto multissetorial, apresentou intensa inclinação ao setor de transportes. Portanto, de um total de 524 projetos, 451 (86\%) foram direcionados ao setor de transportes, 64 (12\%) ao setor de energia e apenas 9 (2\%) ao setor de comunicação. De modo similar, no Portfólio do COSIPLAN, cerca de 461 (86,8\%) foram projetos concernentes ao setor de transporte, restando $61(11,5 \%)$ ao setor de energia e $9(1,7 \%)$ ao setor de comunicações.

O mesmo padrão se manteve em relação aos investimentos destinados a cada setor no Portfólio da IIRSA, no qual o setor de transporte concentrou a maior parcela dos financiamentos de US\$ 55.390,1 milhões (57\%), porém, o setor de energia, apesar de possuir poucos projetos, em razão do fato de serem obras de grande porte, respondeu por uma parcela considerável dos investimentos de aproximadamente US\$ 44.684,4 milhões (42\%), seguido das baixas cifras dedicadas ao setor de comunicação de apenas US\$ 44,7 milhões, menos de 1\%. Situação análoga encontra-se no portfólio do COSIPLAN em que foram destinados US\$ 65.144,6 (56,1\%) ao setor de transporte, US\$ 50.931,3 $(43,86 \%)$ ao setor de energia - que teve seus investimentos ampliados por se tratar de obras de grande porte e apenas US\$ 44,7, novamente menos de $1 \%$, ao setor de comunicação (Tabela 03). 




MAPA 01

Projetos Pontuais e lineares Delimitados pela IIRSA/COSiplan para o Período de 2012 a 2013

Fonte: Elaborado pelos autores. 
Tabela 03 - Composição setorial/subsetorial do portfólio da IIRSA para o ano de 2010 e do COSIPLAN para o ano de 2011 (investimentos em milhões de US\$)

\begin{tabular}{|c|c|c|c|c|c|c|c|c|}
\hline \multirow{2}{*}{ TIPO DE SETOR } & \multicolumn{2}{|c|}{2010} & \multicolumn{2}{|c|}{2011} & \multicolumn{2}{|l|}{2010} & \multicolumn{2}{|c|}{2011} \\
\hline & N. & $\%$ & N. & $\%$ & US\$ & $\%$ & US\$ & $\%$ \\
\hline \multicolumn{9}{|c|}{ TRANSPORTE } \\
\hline Rodoviário & 207 & 39 & 210 & 46 & $32.991,1$ & 34 & $39.506,6$ & 61 \\
\hline Ferroviário & 61 & 12 & 61 & 13 & $12.746,9$ & 13 & $10.784,3$ & 16,5 \\
\hline Fluvial & 74 & 14 & 75 & 16 & $2.837,4$ & 3 & $2.778,7$ & 4 \\
\hline Marítimo & 31 & 6 & 32 & 7 & $3.391,2$ & 3 & $7.885,6$ & 12 \\
\hline Aeroviário & 24 & 6 & 28 & 6 & $2.690,3$ & 3 & $3.273,6$ & 5 \\
\hline Multimodal & 15 & 3 & 14 & 3 & 0,4397 & 0 & 549,9 & 1 \\
\hline Passos de fronteira & 39 & 7 & 41 & 9 & 293,5 & 0 & 365,9 & 0,5 \\
\hline Totais & 451 & 86 & 461 & 86,8 & $55.390,1$ & 57 & $65.144,6$ & 56,1 \\
\hline \multicolumn{9}{|c|}{ ENERGIA } \\
\hline $\begin{array}{l}\text { Harmonização regula- } \\
\text { tória }\end{array}$ & 1 & 0 & 1 & 1,5 & 380,4 & 0 & 380,4 & 1 \\
\hline Geração & 27 & 5 & 26 & 42,5 & $28.433,3$ & 30 & $37.934,3$ & 74 \\
\hline Interconexão & 36 & 7 & 34 & 56 & $11.870,7$ & 12 & $12.616,6$ & 25 \\
\hline Total & 64 & 12 & 61 & 11,5 & $44.684,4$ & 42 & $50.931,3$ & 43,86 \\
\hline \multicolumn{9}{|c|}{ COMUNICAÇÃO } \\
\hline Interconexão & 9 & 2 & 9 & 1,7 & 44,7 & 1 & 44,7 & 0,04 \\
\hline Total & 9 & 2 & 9 & 1,7 & 44,7 & 1 & 44,7 & 0,04 \\
\hline Total Geral & 524 & 100 & 531 & 100 & 96.119 & 100 & $116.120,6$ & 100 \\
\hline
\end{tabular}

Fonte: IIRSA, Portfólio de Projetos 2010 e COSIPLAN, Portfólio de Projetos 2011.

Em virtude da grande insuficiência de investimentos em infraestruturas, certamente, o poder público deve mobilizar uma elevada quantidade de investimentos ao setor. Nesse intento, a fim de comprometer menos o Tesouro Nacional, tornou-se estratégico ao Estado mobilizar novas fontes de recursos, que apresentam sua formação em outras áreas do sistema econômico. Desta maneira, ao ampliar a capacidade de investimento dos setores de serviços públicos, os governos sul-americanos investem esforços para mobilizar a alocação de recursos ociosos da iniciativa privada (especialmente nacional) para os setores subinvestidos (RANGEL, 2005).

No entanto, embora haja um grande esforço para ampliar a participação da iniciativa privada nos projetos, foi o Estado o principal investidor do portfólio da IIRSA, responsável por $46 \%$ dos recursos, seguido pela parceria público-privada com $37 \%$ e o setor privado com $17 \%$. Situação que deve se manter com a COSIPLAN, uma vez que espera-se que o poder público financie $43,5 \%$ dos investimentos, seguido pelas Parcerias Público-Privadas com $41,0 \%$ e o setor privado com 15,5\%.

Depois de demonstrar a distribuição desigual dos projetos e investimentos, discorremos sobre a distribuição setorial das obras e dos financiamentos, além dos principais 
investidores dos projetos. No entanto, ainda torna-se primordial a elaboração de uma última questão. Afinal, qual tipo de obras será realizado em cada setor?

\section{CARACTERIZAÇÃO SETORIAL DAS OBRAS DELIMITADAS NO PORTFÓLIO DA COSIPLAN}

Como constatamos haver mais permanências que mudanças nos Portfólios analisados, responderemos tal questionamento explorando apenas os dados do Portfólio da COSIPLAN (2011), que se apresentavam mais atualizados. Como podemos constatar, grande parcela das obras foram destinadas ao setor de transporte, que centralizou, aproximadamente, $86,8 \%$ dos projetos (Quadro 01).

As rodovias representaram $47,6 \%$ das obras e $51,3 \%$ dos investimentos para a ampliação e reabilitação de antigas estradas, sendo $31,4 \%$ das obras e 18,3\% dos investimentos dedicados à pavimentação de obras novas, aproximadamente, 13,9\% das obras e $11 \%$ dos investimentos voltados à reabilitação de pontes e túneis e, 7,1\% das obras e 19,4\% dos investimentos destinados a anéis rodoviários e acessos as cidades.

Às ferrovias foram destinadas mais de $55,7 \%$ das obras e $79 \%$ dos investimentos à reabilitação de linhas antigas, sendo apenas 34,4\% das obras e 15,2\% dos investimentos destinados à construção de novas linhas, das quais mais de $9,8 \%$ das obras e 5,8\% dos investimentos foram dedicados ao contorno de anéis ferroviários.

As hidrovias tiveram $44 \%$ das obras e $69 \%$ dos investimentos destinados ao melhoramento da navegabilidade nos rios, sendo $45,3 \%$ das obras e $14,4 \%$ dos investimentos voltados à adequação dos portos, e apenas $10,7 \%$ das obras e $16,6 \%$ dos investimentos direcionados à construção de novos portos.

O transporte marítimo teve $68,8 \%$ das obras e $80,3 \%$ dos investimentos para a ampliação das infraestruturas terrestres, $18,8 \%$ das obras e $18 \%$ dos investimentos dedicados à adequação de portos marítimos e apenas 12,5\% das obras e 1,7\% dos investimentos destinados à construção de novos portos.

O transporte multimodal apresentou mais de $85,7 \%$ das obras e mais de $63,1 \%$ dos investimentos dedicados à criação de estações de transferência e 14,3\% das obras e 36,9\% dos recursos destinados à ampliação de capacidade desse tipo de transporte.

Os Postos de Fronteira obtiveram 75,6\% das obras e 59,2\% dos investimentos destinados à implantação de novos centros de controle de fronteira, restando $17,1 \%$ das obras e 39,8\% dos investimentos para o aumento da capacidade dos centros já existentes e 7,3\% das obras e 1,0\% dos investimentos foram para a adequação da infraestrutura existente dos centros de controle.

O transporte aéreo obteve $42,9 \%$ das obras e $88,6 \%$ dos investimentos direcionados para a ampliação de aeroportos, sendo que $21,4 \%$ das obras e $2,1 \%$ dos investimentos foram para a adequação dos aeroportos antigos e 35,7\% das obras e 9,3\% dos investimentos destinados à construção de novos aeroportos.

\section{QUADRO 01}

Composição Subsetorial do POrtfólio da Cosiplan para o AnO de 2011 
Já o setor energético, embora tenha respondido por apenas 61 (11,5\%) dos projetos, geralmente tratava-se de grandes obras de engenharia, havendo a necessidade de uma elevada soma de investimentos, o que ampliou a participação dos mesmos para US\$ $50.931,3$, o equivalente a 43,9\% do total dos investimentos empregado. Deste modo, a distribuição ocorreu da seguinte forma:

I. hidrelétricas: $24,6 \%$ das obras e mais de $63,7 \%$ dos investimentos foram destinados à adequação e à construção de novas centrais;

II. termoelétricas: $6,6 \%$ das obras e 3,6\% dos investimentos foram destinados a novas centrais;

III. carboelétricas e energia nuclear: aproximadamente 4,9\% das obras e 4,6\% dos investimentos dedicados a novas centrais;

IV. infraestrutura energética: cerca de $6,6 \%$ das obras e 2,6\% dos investimentos foram destinados a esse fim;

V. construção de novas interconexões energéticas: aproximadamente $54,1 \%$ das obras e $24,5 \%$ dos investimentos; e

VI. adequação de novas interconexões energéticas e unificação normativa energética: apenas 3,2\% das obras e $1 \%$ dos investimentos.

Por fim, os projetos destinados ao setor de comunicação receberam o menor número de recursos - 9 obras, com investimentos de US\$ 44,7, sendo distribuídos em:

I. rede de fibra óptica: respondeu por $88,9 \%$ das obras e $99,8 \%$ dos investimentos foram aplicados na ampliação entre os países do continente;

II. rede de telecomunicação: absorvendo somente $11,1 \%$ das obras e $0,2 \%$ dos investimentos. Tais dados apresentados podem ser examinados com maior acuidade na Tabela 04.

Ademais, deve-se salientar que, no balanço realizado pela UNASUR no ano de 2011 para avaliar o andamento das obras, por ser herdeira da IIRSA do total de 531 projetos, $63(11,9 \%)$ já estavam concluídos, com investimentos de US\$10.408,9 milhões (9\%), 159 (29,6\%) encontravam-se em execução, com investimentos estimados de US\$ $52.047,0$ milhões $(44,8 \%)$ e $309(58,2 \%)$ obras apresentavam-se em pré-execução ou perfil, com investimentos aproximados de US\$ 53.665,1 (46,2\%).

O COSIPLAN, junto com as permanências advindas da IIRSA, também herdou as polêmicas em que estava envolto o antigo projeto, como os estudos de impactos ambientais insuficientes, além da dificuldade de contemplar as demandas das populações locais para a constituição do Portfólio de obras. Sendo assim, tais impactos socioambientais são sentidos com intensidade diversificada em cada região que abrange o projeto.

Prontamente, averiguou-se na Região Setentrional do Continente um número reduzido de projetos, que canalizaram uma importante soma de investimentos por destinarem-se a construções de hidrelétricas. Sendo assim, por se tratar de uma área em que se localiza a Floresta Amazônica com a presença de áreas de reservas ambientais e terras indígenas (Mapa 02), coerentemente, os impactos das obras da IIRSA/COSIPLAN na região tornaram-se temática de grande parte das análises acadêmicas. No entanto, ao analisar as Agendas e Portfólios da IIRSA/COSIPLAN, percebemos que foi a Região Austral 
do Continente (e parte da Central) que centralizou os maiores percentuais de obras e investimentos (Mapa 01). Tal fato, pouco salientado, justifica-se graças à localização da CAN e principalmente do MERCOSUL nessa área, que concentra projetos destinados ao setor de transporte com a construção de algumas novas obras, mas, sobretudo, investimentos visando à recuperação/ampliação das infraestruturas já existentes no território.

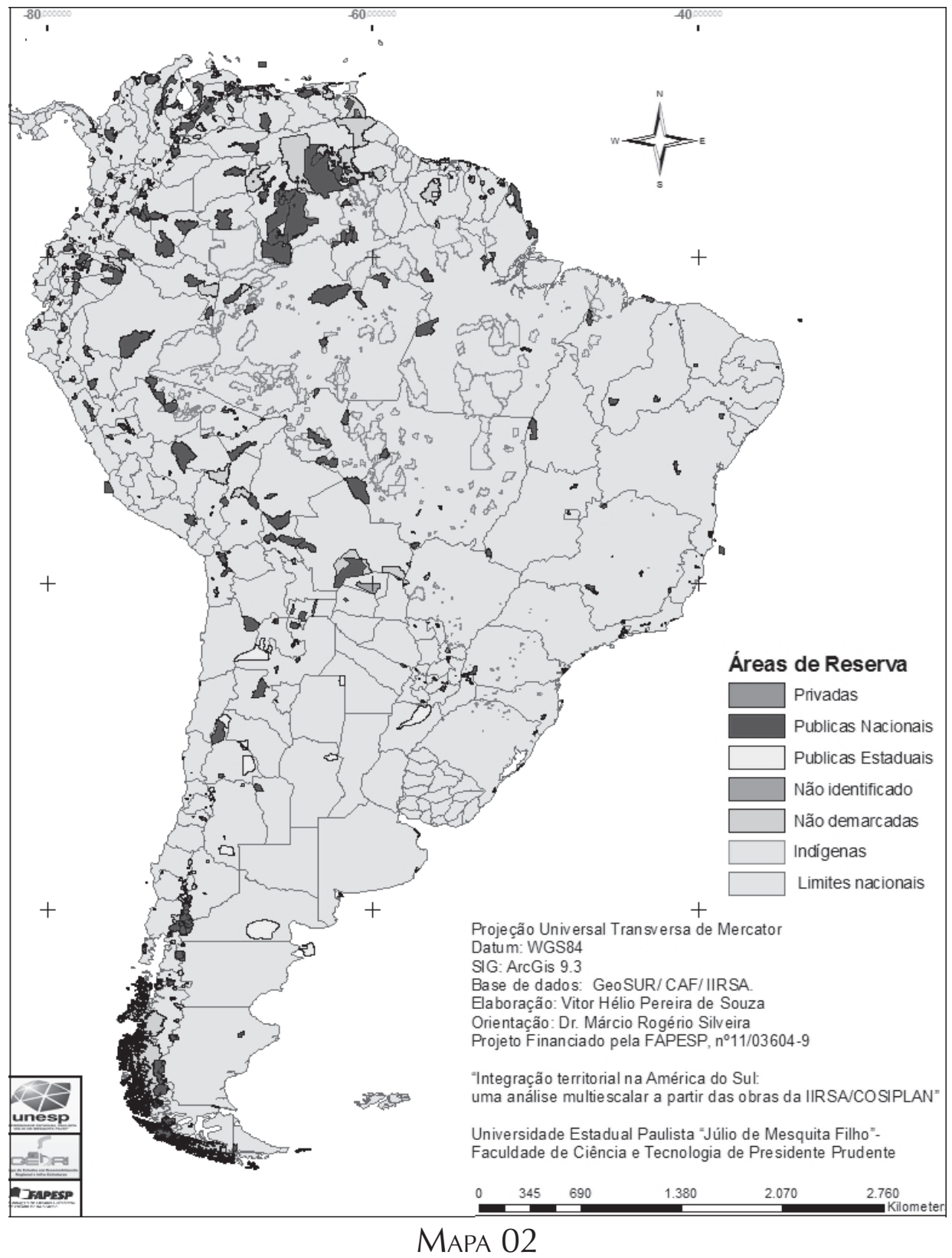

LOCALIZAÇÃO DAS ÁREAS DE RESERVA AMBIENTAL DELIMITADAS NO PROJETO DA IIRSA/COSIPLAN

Fonte: elaboração dos autores. 
Tabela 04 - Discriminação dos projetos e investimentos do portfólio do COSIPLAN 2011

\begin{tabular}{|c|c|c|c|c|}
\hline \multirow[b]{2}{*}{ TIPO DE MODAL } & \multicolumn{2}{|c|}{ PROJETOS } & \multicolumn{2}{|c|}{ INVESTIMENTO } \\
\hline & N. & $\%$ & $\begin{array}{l}\text { MILHÕES } \\
\text { DE US\$ }\end{array}$ & $\%$ \\
\hline \multicolumn{5}{|l|}{ RODOVIÁRIOS } \\
\hline Ampliação da capacidade & 41 & 19,5 & $14.237,7$ & 36 \\
\hline Reabilitação de calçadas e estruturas & 59 & 28,1 & $6.053,3$ & 15,3 \\
\hline Pavimentação de obra nova & 66 & 31,4 & $7.222,7$ & 18,3 \\
\hline Pontes novas e reabilitação & 25 & 11,9 & $2.003,3$ & 5,1 \\
\hline Anéis rodoviários e acesso à cidade & 15 & 7,1 & $7.659,5$ & 19,4 \\
\hline Túneis novos e reabilitação & 2 & 1,0 & $1.850,0$ & 4,7 \\
\hline Manutenção de estradas & 2 & 1,0 & 480,0 & 1,2 \\
\hline Total & 210 & 100,0 & $39.506,6$ & 100,0 \\
\hline \multicolumn{5}{|l|}{ FERROVIA } \\
\hline Construção de ferrovias & 21 & 34,4 & $1.643,3$ & 15,2 \\
\hline Reabilitação de ferrovias & 34 & 55,7 & $8.518,0$ & 79,0 \\
\hline Anéis ferroviários & 6 & 9,8 & 623,0 & 5,8 \\
\hline Total & 61 & 100,0 & $10.784,3$ & 100,0 \\
\hline \multicolumn{5}{|l|}{ FLUVIAL } \\
\hline Melhoramento de navegabilidade & 33 & 44,0 & $1.918,1$ & 69,0 \\
\hline Construção de novos portos fluviais & 8 & 10,7 & 460,6 & 16,6 \\
\hline Adequação de portos existentes fluviais & 34 & 45,3 & 400,0 & 14,4 \\
\hline Total & 75 & 100,0 & $2.778,7$ & 100,0 \\
\hline \multicolumn{5}{|l|}{ MARÍTIMO } \\
\hline Novos portos marítimos & 4 & 12,5 & 133,5 & 1,7 \\
\hline $\begin{array}{l}\text { Ampliação da infraestrutura terrestre de portos marí- } \\
\text { timos }\end{array}$ & 22 & 68,8 & $6.332,8$ & 80,3 \\
\hline Adequação de portos marítimos & 6 & 18,8 & $1.419,3$ & 18.0 \\
\hline Total & 32 & 100,0 & $7.885,6$ & 100.0 \\
\hline \multicolumn{5}{|l|}{ AÉREO } \\
\hline Adequação dos aeroportos & 6 & 21,4 & 70.1 & 2.1 \\
\hline Novos aeroportos & 10 & 35,7 & 304.9 & 9,3 \\
\hline Ampliação de aeroportos & 12 & 42,9 & $2.898,6$ & 88,6 \\
\hline Total & 28 & 100,0 & $3.273,6$ & 100,0 \\
\hline \multicolumn{5}{|l|}{ MULTIMODAL } \\
\hline Estações de transferência & 12 & 85,7 & 347,0 & 63,1 \\
\hline Transporte multimodal & 2 & 14,3 & 202,9 & 36,9 \\
\hline Total & 14 & 100,0 & 549,9 & 100,0 \\
\hline
\end{tabular}


Tabela 04 - Discriminação dos projetos e investimentos do portfólio do COSIPLAN 2011

\begin{tabular}{|c|c|c|c|c|}
\hline \multirow[b]{2}{*}{ TIPO DE MODAL } & \multicolumn{2}{|c|}{ PROJETOS } & \multicolumn{2}{|c|}{ INVESTIMENTO } \\
\hline & N. & $\%$ & $\begin{array}{c}\text { MILHÕES } \\
\text { DE US\$ }\end{array}$ & $\%$ \\
\hline \multicolumn{5}{|l|}{ POSTOS DE FRONTEIRA } \\
\hline $\begin{array}{l}\text { Infraestrutura para implantação de centros de controle } \\
\text { fronteiriço }\end{array}$ & 31 & 75,6 & 216,6 & 59,2 \\
\hline $\begin{array}{l}\text { Adequação da infraestrutura existente em centros de } \\
\text { controle fronteiriço }\end{array}$ & 3 & 7,3 & 3,8 & 1,0 \\
\hline $\begin{array}{l}\text { Ampliação de infraestrutura - capacidade de centros } \\
\text { de controle fronteiriço }\end{array}$ & 7 & 17,1 & 145,5 & 39,8 \\
\hline Total & 41 & 100,0 & 365,9 & 100,0 \\
\hline \multicolumn{5}{|l|}{ ENERGIA } \\
\hline Hidroelétricas novas e adequação de microcentrais & 15 & 24,6 & $32.417,5$ & 63,7 \\
\hline Termoelétrica & 4 & 6,6 & $1.820,0$ & 3,6 \\
\hline Carboelétrica & 1 & 1,6 & 625.0 & 1,2 \\
\hline Geração com energia nuclear & 2 & 3,3 & $1.740,0$ & 3,4 \\
\hline Outras infraestruturas energéticas & 4 & 6,6 & $1.331,8$ & 2,6 \\
\hline Construção de novas interconexões energéticas & 33 & 54,1 & $12.491,4$ & 24,5 \\
\hline Adequação de novas interconexões energéticas & 1 & 1,6 & 125.2 & 0,25 \\
\hline Unificação normativa energética & 1 & 1,6 & 380,4 & 0,75 \\
\hline Total & 61 & 100,0 & $50.931,3$ & 100,0 \\
\hline \multicolumn{5}{|l|}{ COMUNICAÇÃO } \\
\hline Fibra óptica & 8 & 88.9 & 44.6 & 99.8 \\
\hline Redes de telecomunicações & 1 & 11.1 & 0.1 & 0.2 \\
\hline Total & 9 & 100,0 & 44,7 & 100,0 \\
\hline Total Geral & 531 & 100,0 & $116.120,6$ & 100,0 \\
\hline
\end{tabular}

Fonte: UNASUR-COSIPLAN. Cartera de Proyectos 2011. Disponível em <www.iirsa.org >. Acesso em: 1 ㅇjan. 2012.

Ora, ao observar a distribuição dos Eixos de Integração e Desenvolvimento definidos nos Portfólios da IIRSA/COSIPLAN, podemos constatar que os eixos que respondem pelo maior número de obras e investimentos convergem na região do Cone Sul, como é o caso do EIDs MERCOSUL-Chile, Hidrovia Paraguai-Paraná, Capricórnio, Andino do Sul e Sul (Vide figura 01). 


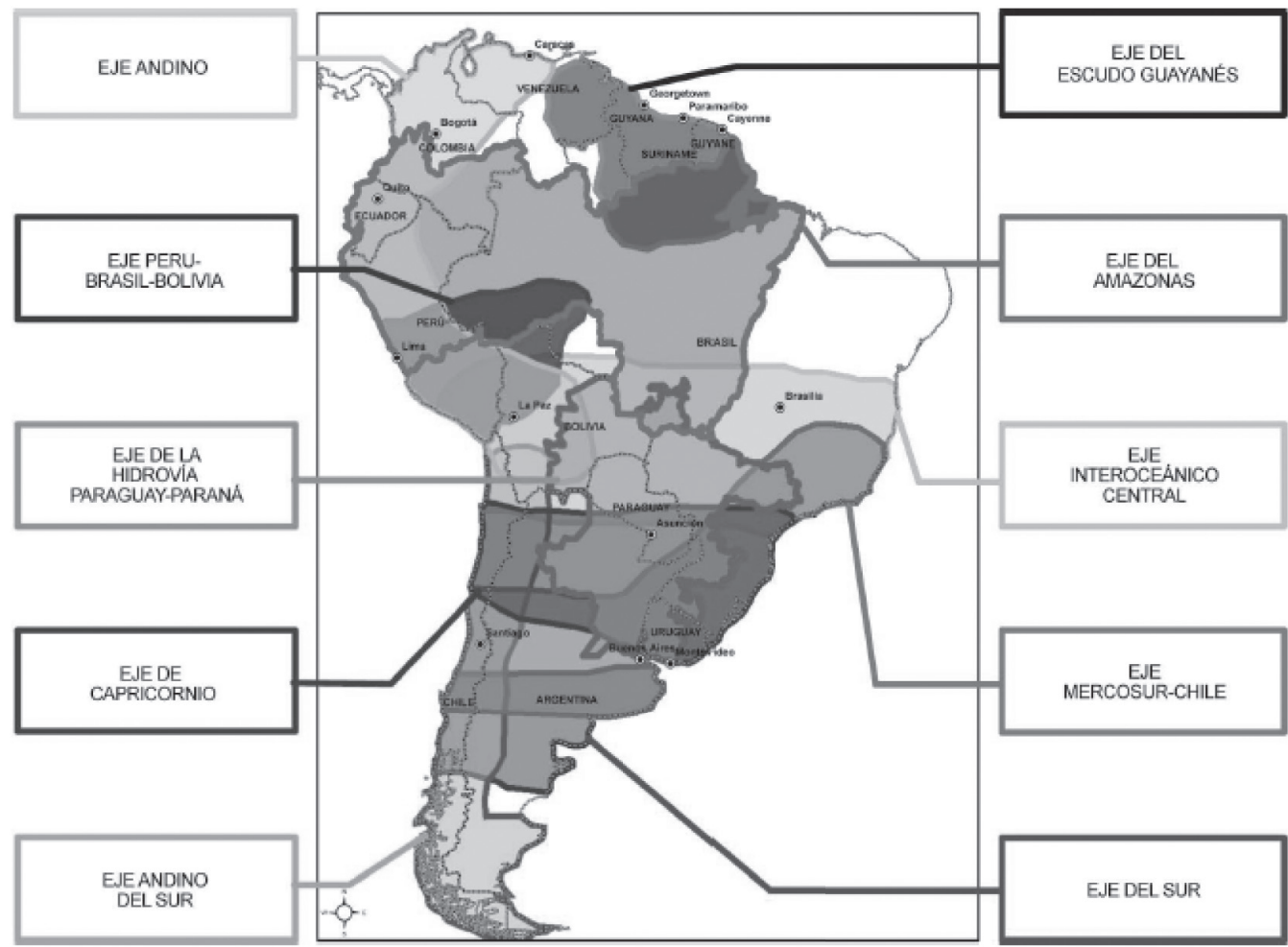

FIGURA 01

Distribuição dos Eixos de INTEGRAÇÃo e DesenVOlVimento (EID)

Fonte: IIRSA, 2011.

Assim sendo, como percebemos, as infraestrutruras e "los corredores están sujetos a la dinámica histórica de conformación y organización de los territórios". Por outro lado, deve-se destacar que "la inercia territorial tiene un fuerte atractivo para la localización de la nueva infraestructura y hay una fuerte influencia de la trayectoria histórica" (PRIEMUS; ZONNEVELD, 2003 apud BLANCO; RODRÍGUEZ, 2011, p. 8).

Prontamente, por se tratar de uma região que concentra as maiores taxas de urbanização, os melhores índices econômicos, assim como o melhor desempenho no comércio internacional intra/extrarregional na/da América do Sul, a área passou a contar também com uma importante soma de investimento, a fim de manter sua atratividade, haja vista que mais de $50 \%$ das obras e investimentos da IIRSA/COSIPLAN foram direcionados para essa região.

\section{CONSIDERAÇÕES FINAIS}

Assim sendo, constata-se uma conformação territorial sul-americana basicamente em forma de "cáscara de huevo", mais densificada na porção litorânea do continente e que se transforma, ao adentrar $100 \mathrm{~km}$ da costa rarefeita, em áreas fronteiriças (FER- 
NÁNDEZ, 2011). Desenho esse que aponta para uma concentração populacional, econômica e de fixos e fluxos secular persistente.

Essa fragmentação territorial contribui para que no primeiro século de colonização iniciassem as aspirações para integração continental. No caso brasileiro, ainda no período imperial, foram elaborados os primeiros planos que visavam interligar o país à Bolívia, finalizando no litoral do Pacífico. Mas, com o risco expansionista e o movimento para formação dos respectivos Estados Nação, esses planos não foram levados adiante.

Sendo assim, no início do século XX, cada país voltou-se para si, com suas respectivas estratégias nacionais de desenvolvimento com intuito de fomentar seus próprios parques industriais e criando um mercado doméstico; para tanto, integrando seu território internamente. Ainda, nesse mesmo século, se avançou na compreensão de que as estratégias nacionais de industrialização poderiam ter nos países da região sua extensão, momento em que se passou a pensar a complementaridade econômica entre os países, assim como a elaboração conjunta dos primeiros planos de infraestrutura de transporte continental.

No entanto, foi somente no início do século XXI que o planejamento das infraestruturas de integração em escala continental foi efetivamente retomado por meio da IIRSA e, consecutivamente, incorporado ao COSIPLAN. Para tanto, ambas as instâncias de planejamento seguiram o mesmo padrão de organização, um Portfólio Geral com mais de 500 obras e uma agenda (AIC e API) com 31 projetos considerados essenciais para a integração regional, que conquistariam maior atenção da academia.

A opção do entendimento da IIRSA/COSIPLAN pela análise dos projetos da AIC/ API resultou na ênfase das pesquisas nas implicações proferidas pelas obras na porção setentrional do continente, na qual localizam-se projetos pontuais, com grandes investimentos destinados à criação de hidrelétricas na região, fator esse que, em razão da fragilidade ambiental da área, conquistou maior enfoque. Porém, é negligenciado o fato que a maior parcela dos projetos e investimentos está concentrada na porção austral do continente, o que demonstra um importante esforço dos países para uma nova geoeconomia/geopolítica na região que ainda carece de maiores estudos.

Desta maneira, a preeminência da Região Austral do Continente, enquanto a área mais estratégica da IIRSA/COSIPLAN, ratifica-se em virtude do fato de nesse recorte espacial localizarem-se a CAN e principalmente o MERCOSUL, concentrando os melhores índices econômicos, assim como o melhor desempenho no comércio internacional intra/extrarregional na/da América do Sul, cuja evolução comercial nas últimas décadas resultou em intensas "interações espaciais" entre os países (SILVEIRA, COCCO, 2010), colocando em destaque os problemas referentes às péssimas condições das infraestruturas de integração existentes.

Nesse ínterim, percebe-se a tendência à seletividade do capital, em sua constante busca para ampliar as "condições gerais de produção" de determinadas áreas em detrimento de outras. Nesse caso, isso fica explícito nas demandas do capital coorporativo ávidas por acelerar, cada vez mais, a circulação do capital, reduzindo o tempo (custo) de transporte das mercadorias, resultando em constantes exigências ao Estado para a ampliação da fluidez territorial, repercutindo na ininterrupta canalização de investimentos pelas parcelas mais dinâmicas economicamente do território. 
Essa concentração de investimentos e projetos, conforme apontamos, ocorre na porção Austral do continente. Porém, ao reduzirmos a escala geográfica de análise, percebe-se que nessa região a distribuição de investimentos e projetos ocorrem também de maneira desigual, reforçando o corredor mais dinâmico economicamente da região, compreendido por Belo Horizonte, São Paulo, Curitiba, Florianópolis, Montevidéu, Buenos Aires, Mendoza, Santiago do Chile e Valparaíso (ARROYO, 2001).

Indubitavelmente, os projetos e investimentos destinados à ampliação da fluidez territorial na porção Austral do continente são imprescindíveis. Contudo, ao verificar quais os tipos de investimentos realizados, constata-se que grande parcela das obras e investimentos foi direcionado ao setor de transportes. Desta maneira, embora todos os modais tenham sido contemplados, verifica-se a permanência do modal rodoviário na centralização dos projetos e recursos.

Por outro lado, ainda que o documento almeje a instalação de novos fixos no território, destacam-se os projetos de recuperação das infraestruturas já existentes, cujo objetivo visa dar novos usos a hidrovias, reativar a utilização de algumas ferrovias, mas, sobretudo, ampliar a capacidade das rodovias, característica limitante do projeto, que não consegue modificar efetivamente a desequilibrada matriz de transporte regional.

Tais aspectos refletem na contínua primazia das áreas seletivizadas pelo capital, a comando das grandes empresas que apresentam maiores interesses na promoção do comércio exterior, não rompendo com a lógica do desenvolvimento desigual e combinado. Todavia, esses projetos promovidos a interesse do capital corporativo resultam também em ganhos para o desenvolvimento em outras escalas geográficas.

Essa premissa justifica-se ao considerarmos que as rodovias que realizam as conexões internacionais são as mesmas que integram as distintas regiões que conformam a rede urbana nacional. Ademais, no caso de alguns municípios e capitais, partes da malha urbana desenvolveram-se no entorno da via, sendo algumas cidades praticamente "conurbadas", casos interessantes em que a "rodovia" também adquiriu função de "avenida", sendo utilizada para mobilidade cotidiana da população (destaque para deslocamentos pendulares), como se verifica em parcelas da BR-101, entre outras rodovias do país e do continente.

Por fim, deve-se destacar, também, que a promoção das infraestruturas de integração, por meio da IIRSA/COSIPLAN, estabeleceu novas convergências geopolíticas/ geoeconômicas para os países envolvidos. A ampliação da fluidez territorial potencializa as interações espaciais existentes e possibilita o estabelecimento de novos intercâmbios entre os países, ainda que as qualidades dessas novas interações não estejam exclusivamente condicionadas às infraestruturas alocadas no território, mas à orientação da política econômica dos países sul-americanos.

\section{BIBLIOGRAFIA}

\subsection{LIVROS E ARTIGOS}

ARROYO, Maria Monica. Território nacional e mercado externo. Uma leitura do Brasil na virada do século XX. 2001.250 p. Tese (Doutorado). Faculdade de Filosofia e Ciências Humanas, Universidade de São Paulo, São Paulo. 
BLANCO, Jorge; RODRÍGUEZ, Diego. Territory, transportation and logistic integration: an approach to the argentinean case. Journal Terrae, Campinas, n. 8, p. 3-12, 2011.

COMISIÓN ECONÓMICA PARA AMÉRICA LATINA Y CARIBE (CEPAL). Unasur: infraestrutura para a integração regional. Santiago do Chile: Nações Unidas, 2012.

COUTO, Leandro Freitas. Política externa brasileira para a América do Sul, As diferenças entre Cardoso e Lula. Revista Civitas, Porto Alegre, v. 10, n. 01, p. 23-44, 2010.

FERNÁNDEZ, Wilson Nerys. IIRSA: desafíos y oportunidades de un megaproyecto controversial. In: MATEO, Manuel Cienfuegos; MELLADO, Noemí Beatriz. (Orgs.). Los cambios en la infraestructura regional y sus impactos ambientales en clave de mejorar la governabilidad en el Mercosur. Córdoba: Lerner, 2011.

RANGEL, Ignácio. Obras Reunidas de Ignácio Rangel. Rio de Janeiro: Contraponto, v. 1 e 2, 2005.

SILVEIRA, Márcio Rogério; COCCO, Rodrigo. Giraldi. Interações espaciais, transporte público e estruturação do espaço urbano. In: Revista Brasileira de Estudos Urbanos e Regionais, v. 12, n. 01, p. 63-81, 2010.

\subsection{DOCUMENTOS}

COMUNIDADE SUL-AMERICANA DE NAÇÕES. Declaração de Cochabamba, 2006. Disponível em:<http://www.unasursg.org> Acesso em: 12 dez. 2010.

INICIATIVA DE INTEGRACIÓN DE LA INFRAESTRUCTURA REGIONAL SUDAMERICANA (IIRSA). Construyendo un nuevo continente: Un enfoque regional para fortalecer la infraestructura suramericana. Washington: IADB/IIRSA, 2006.

. Planificacion Territorial Indicativa. Cartera de Proyectos. Washington: IADB/IIRSA, 2010.

Disponível em < www.iirsa.org.> Acesso em: 12 dez. 2010.

. IIRSA 10 anos depois: Suas conquistas e desafíos. Buenos Aires: BID/INTAL, 2011.

UNASUR-COSIPLAN. Cartera de Proyectos, 2011. Disponível em <www.iirsa.org> Acesso em: $1^{\circ}$ jan. 2012. 